een gevoel van leegte, waardoor artsen onnodig een afwijzende houding kunnen ontwikkelen. Huisartsen zijn hierin vaak in het nadeel omdat ze doorgaans nog solistisch werken, ook al werkt men in een groepssetting. In ziekenhuizen is er vaak het voordeel van een teambespreking, soms vereist in een steeds vaker aanwezig 'euthanasieprotocol'.

3. Daaruit volgt een aantal bijna vanzelfsprekende adviezen:

- Begeef je tenminste de eerste keren niet op het pad van euthanasie zonder intervisie van een oudere, ervaren collega. Kies deze collega zorgvuldig uit. Maak er een gewoonte van of misschien moet dit wel een gewoonte worden: het delen van belastende ervaringen.

- Bespreek de ontwikkelingen van het proces in medische zin, de interacties met patiënt en familie en wat er met je als persoon gebeurt.

- Neem de fasen die tot euthanasie leiden zorgvuldig door: de behandelingen, de ontwikkeling naar het 'ondraaglijk lijden', de besluitvorming, de eisen van de wet, het con- sult en de uiteindelijke uitvoering. Realiseer je dat er, om euthanasie te kunnen uitvoeren, een balans moet zijn tussen het verzoek van een patiënt en je eigen oordeel, op basis van een opgebouwde relatie.

- Ga niet alleen op pad voor de uitvoering, maar doe dit gemeenschappelijk en bereid je tot in detail voor.

- Realiseer je dat het beëindigen van iemands leven altijd een schok teweegbrengt, die een diepe echo van allerlei tegenstrijdige gevoelens oproept. Bespreek deze in een nagesprek met je intervisor/collega.

Misschien is het grootste leerpunt wel dat de gang naar euthanasie en de uitvoering van de laatste handeling nooit 'normaal' zal of mag worden. Waarschijnlijk is dat maar goed ook. Aan euthanasie mag je eigenlijk niet wennen. Hoe men er ook over spreekt: het moet een schok blijven, maar je moet er niet door gaan disfunctioneren. Een goede voorbereiding en ondersteuning is dus geen overbodige luxe.

\title{
De impact van euthanasie op Nederlandse huisartsen
}

\author{
Harm van Marwijk, Ilinka Haverkate, Paul van Royen, Anne-Mei The
}

\section{Introductie}

Een langdurige ziekte, waarvan de patiënt weet dat er een fatale afloop zal zijn, kan pijn en vernedering veroorzaken. Dat is echter niet het enige perspectief: de patiënt krijgt de gelegenheid om na te denken over zijn leven en over 'onafgewerkte zaken'. De arts kan daarbij een sleutelfiguur worden die de patiënt helpt bij het in het reine komen met zijn leven. Veel terminale patiënten gaan nadenken over de zin van het leven. Zij kunnen dan voordeel hebben van een goede relatie met hun huisarts, die voor velen het laatste aanspreekpunt is in de zorg.

Er zijn echter veel moeilijkheden die een rol kunnen spelen, zoals een lastige communicatie met dementerende ouderen en - zoals dat soms bij longkanker gebeurt - vermijdingsgedrag van artsen die nalaten de terminale ziekte een naam te geven. ${ }^{1,2}$

Voor artsen zelf kan het ondersteunen van stervende patiënten een van de meest verrijkende elementen zijn van hun dagelijks werk. Adequate zorg bieden bij het levenseinde is bovendien essentieel in de opbouw van een goede relatie met de familie van patiënten en met de gemeenschap in het algemeen. Nu het begin van het leven, de verloskunde, niet langer een taak is van huisartsen, kan de zorg aan het levenseinde veel bijdragen aan hun tevredenheid over hun werk.
Beslissingen bij het levenseinde kunnen niettemin erg moeilijk zijn en betrokken worden bij een euthanasie kan een zeer grote impact hebben op huisartsen. ${ }^{3} \mathrm{Bij}$ artsen werden emotionele (28\%) en belastende (25\%) gevoelens gerapporteerd, en een algemeen onlustgevoel bij $42 \%$ van alle gevallen van levensbeëindiging, en zeker bij euthanasie (75\%). ${ }^{3,4}$ Vier soorten beslissingsvelden worden omschreven, in volgorde van toenemende onlustgevoelens: verlichting van symptomen, ongevraagde levensbeëindiging, hulp bij zelfdoding en euthanasie.

Op 1 april 2002 werden euthanasie en hulp van artsen bij zelfdoding legaal in Nederland. Onder de Nederlandse wetgeving zijn artsen niet langer strafbaar mits zij een uitgebreide aangifteprocedure volgen en de statutaire vereisten van zorgvuldig handelen in acht nemen. Zie voor meer informatie:

www.minbuza.nl/binaries/en-pdf/faq-euth-2008-en-geupdate020408-eng.pdf.

Omdat er maar weinig, laat staan goed gedetailleerde, informatie bestaat over de emotionele impact die beslissingen over het levenseinde hebben op Nederlandse huisartsen, ${ }^{5-10}$ was ons doel hierover kwalitatieve inzichten te verwerven, mede om die in het onderwijs aan aios huisartsgeneeskunde te kunnen gebruiken. 


\section{Methode}

Wij kozen voor kwalitatief onderzoek, omdat we een relatief nieuw terrein uitgebreid wilden bestuderen. Het onderwerp lag gevoelig, en dit kon het moeilijk maken om artsen te bewegen daarover te spreken. ${ }^{11}$ Daarom achtten wij kwalitatief onderzoek een toereikende manier om een scala aan reacties en mechanismen te bestuderen, te weten: hoe voelen artsen zich erbij, hoe denken zij over deze kwesties, en wat zijn hun attitudes en ervaringen.

\section{Focusgroepen}

Wij kozen voor het werken met focusgroepen om de artsen in staat te stellen hun ervaringen te delen en om een veilige omgeving te creëren voor discussie. ${ }^{12,13}$ Deze methode levert een rijkdom aan details op over complexe ervaringen en verheldert de redenering achter de acties, de overtuigingen en de attitudes. ${ }^{14,15}$ In een focusgroep komen ervaringsdeskundigen samen en dat bevordert de openheid.

Wij ontwikkelden vooraf een vragenplan en testten dat uit in een korte pilot in een afdeling Huisartsgeneeskunde. Een erkend psycholoog met ruime ervaring als moderator van groepen leidde alle focusgroepen. Een onderzoeker ( $\mathrm{IH}$ ) was daarbij aanwezig als observator. Voor de pilotdiscussie vond een focusgroepsessie plaats met vier huisartsen. Een van hen werd geïnterviewd. Op basis van deze discussie en dit interview werd de volgorde van de vragen licht aangepast. Dit had drie algemene thema's als resultaat: 1) ervaren emoties, 2) coping, en 3) de rol van de arts.

\section{Steekproef}

Een lijst van huisartsen uit het westen van Nederland werd samengesteld met de sneeuwbalmethode. ${ }^{16}$ Wij nodigden per telefoon

\section{Samenvatting}

Van Marwijk H, Haverkate I, Van Royen P, The A-M. De impact van euthanasie op Nederlandse huisartsen. Huisarts Wet 2008;51(12)588-93.

Doel Doel van het onderzoek was meer zicht te krijgen op de emotionele impact die het uitvoeren van euthanasie en hulp bij zelfdoding hebben op huisartsen, teneinde de beroepsopleiding te kunnen aanpassen.

Methode Het betreft kwalitatief onderzoek met 4 focusgroepen. Het onderzoek werd gedaan in de Nederlandse huisartsenpraktijk. De 22 deelnemende huisartsen zijn verdeeld in 4 groepen, te weten: oudere mannen, oudere vrouwen, jongere mannen, en een groep met belangstelling voor euthanasie.

Resultaten Er werden drie fasen onderscheiden met verschillende emoties: vóór (spanning), tijdens (verlies) en na (opluchting) de gebeurtenis. Hoewel het maar zeer zelden gebeurt, heeft euthanasie een grote impact op huisartsen. Hun relatie met de patiënt, hun eenzaamheid, de rol van de familie en de druk van de gemeenschap zijn de voornaamste thema's. Het is voor huisartsen belangrijk dat zij voldoende emotionele ruimte en tijd vrijmaken om op een goede manier afscheid te nemen van hun patiënt. meer dan vijftig huisartsen uit om deel te nemen aan het project. De inclusiecriteria waren: minstens één persoonlijke ervaring in het uitvoeren van een euthanasie of hulp bij zelfdoding.

Om een breed scala aan ervaringen te kunnen verzamelen, werden de 22 deelnemende huisartsen verdeeld in 4 exploratieve en beschrijvende focusdiscussiegroepen. De discussies vonden plaats in de periode van augustus tot november 2003. De groepen waren homogeen ingedeeld qua leeftijd en geslacht: zes mannelijke huisartsen in de eerste groep, zes vrouwelijke in de tweede. De meeste huisartsen in deze groepen hadden meer dan twintig jaar praktijkervaring. De derde groep bestond uit vijf mannelijke huisartsen jonger dan 46 jaar (36-45; 2 tot 13 jaar praktijkervaring). De vierde groep bestond uit drie vrouwelijke en twee mannelijke SCEN-huisartsen. SCEN (Steun en Consultatie bij Euthanasie Nederland) ondersteunt huisartsen bij beslissingen en procedures rondom het levenseinde.

\section{Data-analyse}

Alle discussies werden op video- of audiotape opgenomen. Waar beschikbaar werd de exacte tekst uitgeschreven (bij één tape was dat onmogelijk want het apparaat werd gestolen). De gegevens werden geanonimiseerd. Twee onderzoekers met ervaring in kwalitatief onderzoek (IH en AMT) analyseerden de uitgeschreven teksten. Zij gebruikten daarvoor de inhoudsanalyse binnen het codeerkader van drie thema's: 1) emotionele ervaring, 2) coping, en 3) de rol van de arts. ${ }^{17-19}$

\section{Resultaten}

\section{Emotionele ervaringen}

De impact van de eerste ervaring. Veel oudere huisartsen beschrijven

Conclusie Veel huisartsen benadrukten dat jonge artsen vroeg in hun carrière hun opvattingen over euthanasie en andere beslissingen aangaande het levenseinde zouden moeten vormen. Deze onderwerpen moeten volgens ons deel uitmaken van het beroepsopleidingsprogramma.

VUmc, EMGO-instituut, afdeling Huisartsgeneeskunde: Harm van Marwijk, huisarts, universitair hoofddocent huisartsgeneeskunde; Ilinka Haverkate, psycholoog. Universiteit van Antwerpen, Interdisciplinaire Zorg en Geriatrie: Paul van Royen, huisarts, hoogleraar huisartsgeneeskunde; VUmc, EMGO-instituut, afdeling Sociale Geneeskunde: Anne-Mei The, juriste, antropologe.

Correspondentie: hwj.vanmarwijk@vumc.nl.

Mogelijke belangenverstrengeling: Dit onderzoek werd financieel mogelijk gemaakt door een toelage van de VU Verenigingsfondsen (een universitair fonds voor speciale projecten) en door de Huisartsopleiding van het VU Universitair Medisch Centrum (VUmc). De onderzoekers werkten onafhankelijk van financiering.

Dit artikel is een dubbelpublicatie met Huisarts $\mathrm{Nu}$. 
Wat is bekend?

- Huisartsen ervaren het verrichten van euthanasie als een zware emotionele belasting.

\section{Wat is nieuw?}

Bij het verrichten van euthanasie ervaart de huisarts gevoelens van eenzaamheid en van druk door de patiënt, diens familie of de maatschappij.

- Veel huisartsen hebben behoefte aan enige vorm van steun bij en emotionele ruimte voor de verwerking van een euthanasieprocedure.

moeilijk te verwerken en soms zelfs traumatiserende ervaringen, emoties als eenzaamheid en gemengde of tegenstrijdige gevoelens.

Ik heb me heel eenzaam gevoeld. Ik kon het met niemand delen. Wilde verhalen over de politie deden de ronde. Eigenlijk wist niemand te vertellen hoe je euthanasie moest uitvoeren. Ik had geen idee hoe het zou gaan en hoe lang het stervensproces zou duren. Ik voelde me machteloos en alleen.' ( $\mathrm{L}$, vrouw)

'Ik vond het de eerste keer erg moeilijk en eenzaam, maar achteraf vond ik dat ik iets goeds had gedaan.' (B, vrouw)

Eén huisarts sprak over het ontbreken van formele procedures in die tijd.

'Het was moeilijk dat je je niet wettelijk hoefde te verantwoorden.' (P, vrouw)

Toentertijd was er veel minder medische expertise beschikbaar over palliatieve zorg en dat maakte emoties los bij de huisartsen. Het hielp hun echter ook om hun pijnlijke ervaringen met anderen te delen, bijvoorbeeld een langdurig stervensproces of een patiënt die na een tijdje weer bij bewustzijn kwam. Verschillende artsen voelden zich schuldig dat zij de procedure niet sneller en efficiënter hadden uitgevoerd.

'Ik had in het eerste jaar geen steun en ik wist er te weinig van.' ( $L$, vrouw)

Sommige oudere huisartsen - meer mannen dan vrouwen - hadden heroïsche gevoelens omdat zij in staat waren iemand te helpen.

'Ik was gevleid door het vertrouwen.' (S, man)

Sommige huisartsen hadden spijt van de eerste euthanasie die ze hadden uitgevoerd, omdat ze onvoldoende op de hoogte waren van de palliatieve mogelijkheden, 'gemanipuleerd' waren door de familie of de patiënt en ze niet alles onder controle hadden. Zij beschreven hun ervaringen als pionierswerk: 'Wij leerden toen al doende.'

Er was verschil tussen de eerste en de globale impact. De huisartsen hadden vóór, tijdens en na het uitvoeren van een euthanasie andere emoties.

'Ik was gespannen. Ik was me er sterk van bewust dat de patiënt HIV had en ik vond het eng. Ik was heel erg bezig met de technische kant van de zaak.' (L, vrouw)

a) Spanning vóór de uitvoering. Velen hadden die emotie, en vertelden dat in hun eigen woorden.
'Het was vreselijk eng. Ik ben nog nooit met zoveel lood in mijn schoenen ergens heen geweest als die ochtend met mijn tasje met het drankje erin.' (T, man)

b) Verlies gedurende de uitvoering. Enkele artsen beschreven hun gevoel van verlies en verlatenheid als de patiënt afscheid nam. Eén arts vertelde hoe emotioneel hij dat moment vond en hoe hij werd geraakt door de liefde en de betrokkenheid van de familie. Deze arts voelde zich er niet zeker over waar hij zijn grenzen moest leggen. Veel artsen ervaren de medisch-technische kant als 'eng': in de thuissituatie, met een terminaal zieke patiënt die een zeer povere circulatie heeft, kan het moeilijk zijn een ingangsweg voor het product te vinden of vast te stellen of de patiënt overleden is. $\mathrm{Zij}$ voelden zich onder druk staan om te slagen.

'Wat ik het moeilijkst vond aan het uitvoeren van euthanasie was het vinden van een ader.' (H, vrouw)

c) Opluchting na de uitvoering. Veel artsen voelden zich opgelucht dat zij iets voor de patiënt hadden kunnen doen. Als alles goed verliep, voelden ze grote voldoening. Maar een aantal artsen zei dat zij toch de grootste opluchting voelden als de vraag om euthanasie of hulp bij zelfdoding werd ingetrokken.

'Als de patiënt een natuurlijke dood sterft, vind ik dat zeer bevrijdend.' (G, man)

'Ik heb niettemin nog altijd een schuldgevoel. Ik denk: ik ben een beul. Wie ben ik om dat te kunnen doen.' (G, man)

Patiënt-dokterrelatie. Enkele artsen, vooral uit de oudere groep, gaven aan dat zij alleen een euthanasie konden uitvoeren als zij op z'n minst een minimale relatie hadden met de patiënt.

'Ik wil vóór de euthanasie een relatie opbouwen met de patiënt, met mezelf in contact blijven.' (C, vrouw)

Eén arts had zelfs suïcidale gedachten terwijl zij zich voorbereidde op de uitvoering van een euthanasie.

'Ik moet heel veel om iemand geven om euthanasie te kunnen doen. Ik heb alleen euthanasie gedaan bij mensen die ik goed kende... Je voelt een verlies als zo iemand sterft. Ik zat toen vooraf in mijn auto en voelde me zo ongelukkig. Ik dacht: als ik dat drankje nu zelf drink, dan is dit allemaal voorbij. Ik heb er zelfs enkele druppels van genomen...' (L, vrouw)

Eenzaamheid. Veel artsen uit alle groepen spraken over eenzaamheid en dat ze hun emoties met niemand konden delen. Een arts uit de SCEN-groep:

'Je hebt een gevoel van eenzaamheid dat andere mensen niet kunnen aanvoelen. Ik vind het ook niet nodig dat met iemand te delen, behalve misschien met collega's.' (A, vrouw)

Familie. De huisartsen vermeldden uiteenlopende gevoelens over de rol van de familie: van dankbaarheid en voldoening tot manipulatie en spanning, en soms zelfs conflict. 
Wat mij nog het meest is bijgebleven, is de betrokkenheid van de familie. Ze leefden allemaal mee. Ik vond dat uniek en ik stond daar met tranen in mijn ogen.' (E, man)

'Ik wist niet hoe de kinderen zouden reageren na de euthanasie.' (D, man)

Eén huisarts beschreef een meningsverschil over het wel of niet rapporteren van de euthanasie aan de overheid. Hij wilde dat wel, de familie niet. Hij had achteraf spijt dat hij niet bij zijn eigen standpunt was gebleven. Sommige artsen vertellen zich gemanipuleerd te voelen. De zoon van een patiënt vroeg bijvoorbeeld aan de huisarts: 'Hoe lang duurt het nog met moeder?' Een veelvoorkomende vraag is ook wie bij de patiënt moet zijn als de euthanasie wordt uitgevoerd.

'De halve familie zat in de kamer en zei: "We gaan nu vijf minuten naar buiten en als we terugkomen is het klaar." Ik voelde me vreselijk gemanipuleerd.' (H, vrouw)

\section{Coping}

'Mijn eerste en enige euthanasiegeval was in 1998. De patiënte had verscheidene metastasen van een primaire tumor en bij het eerste consult vroeg ze om euthanasie. Ik voelde achteraf dat ik niet in het reine was met mijn opvattingen. In Nederland geldt dat je niet hoeft te lijden en dat je om euthanasie kunt vragen. Ik voelde me min of meer gepakt en was kwaad. Mijn partner is ook huisarts. Zij stopte meer dan een jaar na enkele zeer moeilijke terminale patiënten.' (K, man)

Euthanasie is een drastische en soms traumatische gebeurtenis voor de huisartsen die erbij betrokken zijn. Zij kunnen daarna hun dagelijkse routine niet zomaar hervatten.

De tijd nemen. Veel artsen vinden het belangrijk om tijd te maken voor zichzelf na een euthanasie of hulp bij zelfdoding. Dit om na te kunnen denken over wat is gebeurd, om afscheid te nemen of om te relaxen. Zij wijten het aan hun drukke bezigheden dat zij het moeilijk vinden om met euthanasie om te gaan. Hoe ermee om te gaan is voor elke arts een persoonlijke opgave.

Meedelen. Om in het reine te komen met het verlies werd met nadruk het belang gemeld van het praten over wat is gebeurd, het direct erna stoom kunnen afblazen en het delen van de ervaring met collega's, de partner of een goede vriend.

'Wij hebben een ritueel dat mijn partner er ook over moet weten. Zij is ook huisarts en weet hoe lastig het kan zijn. Zij wacht dan af. Ik heb er toch wel vaak last van de volgende dag. Dan denk ik: donder op, ik wil ruimte. Een jaar geleden had ik een sabbatical. Ik merkte dat allerlei mensen die dood waren in mijn hoofd zaten. Niet alleen de mensen die door euthanasie waren overleden. Het sneeuwt helemaal onder bij mij. Een ritueel zou goed zijn voor mij, en die tijd is er gewoon niet. De herbeleving van een posttraumatische stressstoornis heb ik niet. Het is de gespletenheid van de opdracht: die persoon moet dood en de sociale verantwoordelijkheid die de huisarts heeft.' (G, man)

De meeste artsen uit de jongere leeftijdgroep benadrukten het belang van de steun van collega's. Het is goed als er hulp is van een ervaren arts die naar hen luistert en raad geeft, en dat ze kun- nen rekenen op collega's die helpen bij de gebeurtenis zelf.

'Ik kan er thuis niet over praten, maar ik heb een toetsingsgroepje met medehuisartsen. En ook een beetje spuien bij de praktijkassistente is al heel fijn.' (S, man)

'Het meeste deel ik met mijn assistente, omdat die de mensen kent. Na één euthanasie heb ik uitgebreide psychologische hulp gehad.' (A, vrouw)

\section{De rol van de arts}

Dilemma's en druk. Sommige huisartsen gaven aan dat zij geen problemen hadden met een vraag om euthanasie en dat ze het hun plicht vonden om die vraag te honoreren. Maar velen van hen worstelen - of hebben dat gedaan - met het dilemma waarom zij als dokters een leven moeten beëindigen. Veel huisartsen voelen dit aan als een ontoelaatbare dwang van de maatschappij.

'In de VS voeren lieden de doodstraf uit op bevel van een rechter. In Holland worden wij als huisarts op die manier aangesteld om iemands leven te beëindigen.' (A, vrouw)

Diverse huisartsen vragen zich af of zij de plicht hebben euthanasie uit te voeren en hoe zij hun eigen inzichten kunnen verdedigen. Met de tijdgeest meegaan, een 'moderne dokter' zijn, speelt in dat opzicht een rol. Sommigen verkiezen geen euthanasie uit te voeren.

'Toen euthanasie nog niet speelde, vond ik het sterfbed een bijzonder aspect van het vak. Het was een eer om iemand bij het afscheid te mogen begeleiden. Bij euthanasie heb ik altijd het gevoel "was dat nou nodig?" Ik ben van mening dat de patiënt de tijd niet meer krijgt voor een natuurlijk stervensproces. Hij wordt opgezadeld met de vraag "wil ik euthanasie?" Door de mogelijkheid om zelf te bepalen wanneer je doodgaat, is er een ontzettende onrust rond het sterfbed ontstaan.' (V, man)

Een aantal mannelijke huisartsen in de jongere leeftijdsgroep gaf aan dat zij het niet vanzelfsprekend vonden om op een vraag om euthanasie in te gaan. Eén huisarts zei dat hij het nog niet wist; hij had het probleem nog niet zorgvuldig genoeg overdacht. Hij vond dat het onderwerp euthanasie met patiënten moest worden besproken

Een ex-SCEN huisarts:

'We waren wel gek dat we het deden, als je er nu op terugkijkt. Wie ben ik dat ik dat doe? Euthanasie komt op míjn bord. Het is een rotklus. Ik vond het blijkbaar normaal voor dokters om dit te doen. Hoe hebben we ons dat op de hals gehaald? Ik voel mij erin geluisd. Ik wilde belangrijk zijn. Ik zou willen dat het mij niet meer gevraagd wordt, maar dat durf ik niet te zeggen. Misschien durf ik dat over een paar jaar. Ik voel me heel erg nabij de mensen, maar ik voel ook boosheid. Wat denken jullie wel, dat je dat aan mij kunt vragen.' (G, man)

Ontwikkeling en ouder worden. Ervaring heeft de huisarts geleerd om met de verschillende aspecten van euthanasie om te gaan. De meesten zijn terughoudend geworden om euthanasie toe te passen. Zij schermen zich meer af, zeggen dat ze hun lesje hebben geleerd en dat ze zich meer aan hun principes houden. Ze zijn 
beter bestand tegen manipulatie

"Toen dacht ik dat ik iets geweldigs had gedaan. Nu weet ik niet meer of het wel goed voor me is.' ( $\mathrm{N}$, vrouw)

Geen euthanasie meer. Een aantal van de huisartsen heeft besloten geen euthanasie meer uit te voeren.

'Ik heb er lang over gedaan voordat ik kon zeggen: "Ik denk dat dit niet goed voor me is. Ik moet iets doen waar ik niet achter sta." Ik doe nu geen euthanasie meer. Ik ben nu veel rustiger.' (V, man)

'Ik zeg nu duidelijk tegen iedereen dat ik geen euthanasie meer doe. Ik zei tegen mezelf: "Ik doe dit nooit meer, dit doe ik mezelf niet meer aan." Tot mijn verbazing zegt een aantal mensen: "Dokter, u hebt groot gelijk, ik snap het helemaal." Toen dacht ik: hoe diep gaan die verzoeken eigenlijk? Ik vond dat onthutsend om te merken.' (A, vrouw)

Reglementering. De artsen vonden het een positieve ontwikkeling dat ze gesteund werden door regels als de uitgebreide meldingsplicht en de publicatie van aanbevelingen voor goede praktijk. Zij waardeerden ook de verbetering van de medisch-technische expertise en de toegenomen kennis van de palliatieve zorg.

'Ik vind het nu allemaal veel makkelijker. Je bespreekt het verzoek om euthanasie met verschillende mensen. Er zijn regels voor. Je laat iemand over je schouder meekijken. Ik vind dat beter.' (L, vrouw)

Euthanasie en palliatieve zorg. Verschillende huisartsen - vooral uit de SCEN-groep - die meer opleiding in palliatieve zorg hadden gekregen, beschreven een groeiende trend naar sedatie en meer palliatieve zorg. Dezelfde trend valt op in verschillende Nederlandse onderzoeken. ${ }^{20}$ De SCEN-artsen, met hun speciale interesse, voegden weinig inzichten toe aan de discussies. Over het algemeen hadden zij intensere ervaringen met beslissingen aan het levenseinde. Eén huisarts had bijvoorbeeld veel terminaal zieke aidspatiënten.

'Ik kan nu, met mijn palliatieve kennis, nee zeggen zonder de patiënten in de kou te laten staan. Ik wil palliatief goed kunnen zijn, en euthanasie goed kunnen doen. Ik wil mij daar zelf goed bij voelen.' ( $L$, vrouw, SCEN-groep)

\section{Bespreking}

Deze kwalitatieve studie geeft een beschrijving van de verschillende persoonlijke ervaringen van Nederlandse huisartsen bij het uitvoeren van euthanasie. Op grond van kwalitatief onderzoek valt nog niet generaliseren, ${ }^{21,22}$ maar toch kan deze informatie van belang zijn, bijvoorbeeld voor het onderwijs. Hoewel artsen vanzelfsprekend rekening moeten houden met de noden van de patiënt en zijn familie, moeten zij evenzeer hun eigen noden laten gelden. Ze moeten hun persoonlijke mening kunnen vormen, hun beslissingsproces vooraf met een collega kunnen bespreken, een collega kunnen vragen aanwezig te zijn bij de euthanasie, nadien 'stoom kunnen afblazen' en tijd voor zichzelf kunnen maken.

De openheid die wij kregen in Nederland, was blijkbaar heilzaam als men de ervaringen van de jongere artsen overziet. Vooral rond het doodsbed zijn een goede relatie en communicatie met de patiënt en zijn familie essentieel. ${ }^{24}$ De arts moet kunnen omgaan met diverse en complexe externe krachten: hij moet bestand zijn tegen druk, en soms zelfs 'manipulatie' kunnen weerstaan. Eerder onderzoek heeft aangetoond dat huisartsen die positief staan tegenover euthanasie, zich soms gedwongen voelen door patiënten om hun deze optie aan te bieden vanwege de hopeloze situatie waarin zij zich kunnen bevinden. ${ }^{4}$

Veel huisartsen raden jonge collega's aan vroeg te beginnen met het ontwikkelen van hun standpunten over euthanasie en andere beslissingen rond het levenseinde. Onderwijsgevers kunnen aios stimuleren bij het ontwikkelen van een visie op dood en sterven. Vooral de oudere artsen zeiden dat zij een lange weg hadden moeten afleggen om zich (meer) bewust te worden van hun eigen inzichten. De trend die bij artsen is ontstaan om dichter bij hun eigen overtuigingen te blijven, is mogelijk voor de jongere generatie een les. De uitspraken van de jongere artsen laten zien dat ze vaker deze houding aannemen en dat ze dikwijls hulp krijgen van ervaren collega's. Meer gelegenheid tot reflectie zou voor huisartsen de omgang met morele kwesties, zoals euthanasie, kunnen verbeteren. ${ }^{4}$

\section{Literatuur}

1 The AM, Pasman R, Onwuteaka-Philipsen B, Ribbe M, Van der Wal G. Withholding the artificial administration of fluids and food from elderly patients with dementia: ethnographic study. BMJ 2002;325: 1326

2 The AM, Hak T, Koeter G, Van der Wal G. Collusion in doctor-patient communication about imminent death: an ethnographic study. BMJ 2000;321:1376-81.

3 Haverkate I, Van der Heide A, Onwuteaka-Philipsen BD, Van der Maas PJ, Van der Wal G. The emotional impact on physicians of hastening the death of a patient. Med J Aust 2001;175:519-22.

4 Hermsen MA, Ten Have HA. Moral problems in palliative care practice: a qualitative study. Med Health Care Philos 2003;6:263-72.

5 Ponsioen BP. How does the general practitioner learn to live with euthanasia? Ned Tijdschr Geneeskd 1983;127:961-4.

6 Emanuel EJ, Daniels ER, Fairclough DL, Clarridge BR. The practice of euthanasia and physician-assisted suicide in the United States: adherence to proposed safeguards and effects on physicians. JAMA 1998;280:507-13

7 Reagan P. Helen. Lancet 1999;353(9160):1265-7.

8 Clark CC, Kimsma GK. "Medical friendships" in assisted dying. Camb Q Healthc Ethics 2004;13:61-7.

9 Obstein KL, Kimsma G, Chambers T. Practicing euthanasia: the perspective of physicians. J Clin Ethics 2004;15:223-31.

10 Kimsma G, Clark C, Van Leeuwen E. Euthanasie stelt unieke eisen Medisch Contact 2008;33/34:1350-3.

11 Silverman D. Doing qualitative research. London/California/New Delhi: Sage Publications, 2000.

12 Morgan D. The Focus Group Guidebook. Focus Group Kit I. London/ New Dehli: Sage publications, 1998

13 Krueger R, Casey M. Focus group: a practical guide for applied research. London/New Dehli: Sage publications, 2000.

14 Kitzinger J. Qualitative research. Introducing focus groups. BMJ 1995 311:299-302.

15 Pope C, Ziebland S, Mays N. Qualitative research in health care. Analysing qualitative data. BMJ 2000;320:114-6.

16 Marshall MN. Sampling for qualitative research. Fam Pract 1996; 13:522-5.

17 Haverkate I, Onwuteaka-Philipsen BD, Van der Heide A, Kostense PJ, Van der Wal G, Van der Maas PJ. Refused and granted requests for euthanasia and assisted suicide in the Netherlands: interview study 
with structured questionnaire. BMJ 2000;321:865-6.

18 Haverkate I, Van der Wal G. Policies on medical decisions concerning the end of life in Dutch health care institutions. JAMA 1996;275(6):435-9.

19 Pope C, Van Royen P, Baker R. Qualitative methods in research on healthcare quality. Qual Saf Health Care 2002;11:148-52.

20 Van der Heide A, Onwuteaka-Philipsen BD, Rurup ML, Buiting HM, Van Delden JJ, Hanssen-de Wolf JE et al. End-of-life practices in the Netherlands under the Euthanasia Act. N Engl J Med 2007;356:1957-65.
21 Britten N. Qualitative Research: Qualitative interviews in medical research. BMJ 1995; 311:251-3.

22 Green J, Britten N. Qualitative research and evidence based medicine. BMI 1998; 316:1230-2.

23 Swarte NB, Van der Lee ML, Van der Bom JG, Van den Bout J, Heintz AP. Effects of euthanasia on the bereaved family and friends: a cross sectional study. BMJ 2003; 327:189.

\section{Vroegdiagnostiek van melanomen}

W. Bergman en K. Reenders noemen in het artikel 'Vroegdiagnostiek van melanomen door huisarts en dermatoloog' (Huisarts Wet 2008;51:501-4) de mogelijkheden van diagnostiek door de huisarts, zoals excisie met een marge van $2 \mathrm{~mm}$ en PA-onderzoek, of verwijzing naar de dermatoloog. De auteurs bespreken vervolgens de mogelijkheid van dermatoscopie in de tweede lijn. Mij verbaast het dat in een huisartsentijdschrift de mogelijkheid van dermatoscopie in de eerste lijn geen verdere aandacht krijgt. Het is een eenvoudig hulpmiddel, waarmee je snel extra informatie krijgt. De dermatoscoop is een los te verkrijgen apparaat en is te gebruiken op dezelfde batterijhouder die in veel huisartsenpraktijken al aanwezig is voor de otoscoop en de oftalmoscoop

Scholing in dermatoscopie verbetert de detectie van melanomen. In Australië ligt de incidentie van melanomen hoger dan in ons land, en is vroegtijdige detectie nog belangrijker. Bij een Australisch onderzoek naar de sensitiviteit van dermatoscopie in de eerste lijn toonde men aan dat de sensitiviteit van de diagnose melanoom door scholing van huisartsen verhoogd kan worden tot $75,9 \%{ }^{1}$ Scholing via cd-rom en internet heeft bewezen resultaat, ook bij niet- ervaringsdeskundigen. $^{2}$ Mijn persoonlijke ervaring is dat individuele nascholing onder andere door cd-roms goed mogelijk is, en dat gebruik van de dermatoscoop in de eerste lijn meerwaarde heeft. Vooral bij twijfel tijdens inspectie kan het een graadmeter zijn voor geruststelling, biopsie, excisie met ruime marge en PA, of doorverwijzing.

Maarten Brinkhuijsen
1 Westerhoff K, McCarthy WH, Menzies SW, Increase in the sensitivity for melanoma daignosis by primary care physicians using skin surface microscopy. Br J Dermatol 2000;143:1016-20.

2 Pagnanelli G, Sover HP, Argenziano G, et al. Diagnosis of pigmented skin lesions by dermatoscopy: web-based training improves diagnostic performance of nonexperts. Br J Dermatol 2003;148:698-702

\section{Antwoord}

In de laatste versie van de CBO Richtlijn Melanoom van de huid ${ }^{1}$ staat: dermatoscopie verhoogt de accuratesse van de klinische diagnose aanzienlijk. Het evidenceniveau was Al op grond van de literatuur. $^{2-4}$ Eén van de aanbevelingen voor de praktijk luidt dan ook: dermatoscopie verdient een vaste plaats te krijgen in de klinische diagnostiek van gepigmenteerde huidafwijkingen. Onervaren artsen zouden zich in deze techniek eerst moeten bekwamen alvorens deze toe te passen. Dermatoscopie door niet-ervaren clinici leidt tot een vermindering van de klinische accuratesse. $^{5}$

In het door collega Brinkhuijsen aangehaalde onderzoek ${ }^{6}$ nam de sensitiviteit (terecht vastgesteld melanoom) bij huisartsen die geschoold werden in de dermatoscopie vergeleken met het 'blote oog' toe van 63 naar 76\%, maar de specificiteit (terecht benigne pigment-dermatosen) bleef nagenoeg gelijk (54 naar 58\%). Er is winst behaald, maar 1 op de 4 melanomen worden 'gemist'. In een ander onderzoek, waarin naast het Australische onderzoek 12 andere werden beschreven, bleek de sensitiviteit bij de huisartsen zowel met het 'blote oog' als na dermatoscopie veel lager te liggen, en was daardoor de 'winst' door de dermatoscopie relatief groot. ${ }^{7}$
De 'blote-oogbeoordeling' blijft echter van doorslaggevend belang en gebruik van de dermatoscoop compenseert niet een niet-optimale vaardigheid in de klinische diagnostiek van gepigmenteerde laesies. Het lijkt ons nuttig dat huisartsen met speciale belangstelling voor dit onderwerp hun diagnostiek middels een dermatoscopietraining leren verfijnen. De methode is ook inzetbaar bij andere dermatosen, zoals het vinden van een mijt bij scabiës. Op 6 februari 2009 is er een praktische Boerhaave Cursus Dermatoscopie die is opengesteld voor geïnteresseerde huisartsen.

1 Richtlijn Melanoom van de huid. Utrecht: Vereniging van Integrale Kankercentra (VIKC) en Kwaliteitsinstituut voor de Gezondheidszorg CBO, 2005.

2 Mayer J. Systematic review of the diagnostic accuracy of dermoscopy in detecting malignant melanoma. Med L Aust 1997; 167:206-10

3 Bafounta ML, Bauchet A, Aegerter P, Saiag P. Is dermoscopy useful for the diagnosis of melanoma? Results of a meta-analysis using techniques adapted to the evaluation of diagnostic tests. Arch Dermatol 2001;137:1343-50

4 Kittler H, Pehamberger $\mathrm{H}$, Wolff $\mathrm{K}$, Binder M. Diagnostic accuracy of dermoscopy Lancet Oncol 2002;3:159-65.

5 Binder M, Puespoeck-Schwarz M, Steiner A, Kittler $\mathrm{H}$, Muellner $\mathrm{M}$, Wolff $\mathrm{K}$, et al. Epiluminescence microscopy of small pigmented lesions: short-term formal training improves the diagnostic performance of dermatologists. J Am Acad Dermatol 1997;36:197-202

6 Westerhoof K, McCarthy WH, Menzies SW. Increase in the sensitivity for melanoma diagnosis by primary care physicians using skin surface microscopy. Br J Dermatol 2000; 143:1016-20

7 Kittler H. Dermatoscopy of pigmented skin lesions. G Ital Dermatol Venereol 2004;139:541-6 